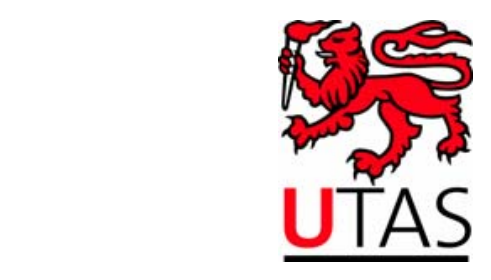

SCHOOL OF ECONOMICS AND FINANCE

Discussion Paper 2007-09

The Determinants of the Quantity-Quality Balance in Monopoly

Hugh Sibly

ISSN 1443-8593

ISBN 978-1-86295-434-2 


\title{
THE DETERMINANTS OF THE QUANTITY-QUALITY BALANCE IN MONOPOLY*
}

\author{
Hugh Sibly \\ School of Economics \\ University of Tasmania \\ GPO Box 252-85 \\ Hobart Tas 7001
}

Email: HSIBLY@POSTOFFICE.UTAS.EDU.AU

Ph: (03) 62262825

Fax: (03) 62267587

(IDD code $+61+3+$ )

November 2007

\begin{abstract}
This paper describes how a monopolist manipulates the balance of quantity and quality in order to increase revenue when its customers treat quantity and quality as substitutes. This 'skewing' of quality depends on the characteristics of customer's demand for quality. Customers differ in demand for quality, because they differ in either (i) their preferences and/or (ii) their time cost per unit. The monopolist is constrained to supply the same quality of good to all customers. The price and quality per unit are described under the assumption the monopolist (i) profit maximises; (ii) maximises social welfare subject to a profit constraint. The determinants of the skewing of quantity and quality are found under third degree price discrimination and uniform pricing.
\end{abstract}

JEL Classification: D42, D11, L15; ePrint Code: 340100.

\footnotetext{
* This paper extends the analysis of Sibly (2004).
} 


\section{The Determinants of the Quantity-Quality Balance in Monopoly}

Customers often differ in the relative importance they place on the quality of a product. However, producing different varieties of a product with different quality levels is costly. Thus, even when the heterogeneity in customer preference for quality provides a significant benefit to vertical differentiation, this may prove too costly to be profitable. For example, coffee shops usually provide customers with only one quality level of coffee (although coffee is usually horizontally differentiated), even when customers have a heterogeneous demand for quality. Clearly there are numerous analogous examples. In addition, political considerations may require provision of uniform quality in regulated or government controlled industries, even if the product can be vertically differentiated at relatively modest cost.

How do the various characteristics of the coffee shop customers' demand influence the level of quality chosen by the coffee shop? More generally, what aspects of customer demand determine the quality level chosen by monopolist? This paper presents a model that provides an answer to these questions. In the model customers are assumed to treat quantity and quality as substitutes. Customers differ in demand for quality because they differ in either (i) their preferences and/or (ii) their income (more specifically, their opportunity cost of time). The monopolist who sells to these customers is constrained, either for cost or political reasons, to supply every market segment (customer type) with the same level of quality. The model identifies the influence each customer type has on the quality level chosen by the monopolist.

The technical difficulties associated with dealing with utility functions which allow for the substitutability of quality for quantity for has resulted in the overwhelming bulk of the literature since Spence (1975) and Sheshinski (1976) following Mussa and Rosen’s (1978) lead in assuming each customer has unit demand. ${ }^{1}$ The assumption of unit demand is clearly

\footnotetext{
${ }^{1}$ For an indication of the difficulties of analysing models with arbitrary consumer preferences (in the context of a multiproduct monopolist) see Armstrong (1996) and Sibley and Srinagesh (1997). Note these papers are complicated by the considerations associated with a multidimensional screening problem; though also consider the case of nonlinear pricing which is technically relatively straightforward compared to uniform pricing. Sappington (2005) provides a survey of the evolution of the analysis of quality in regulated industries.
} 
not entirely satisfactory to model the common situations in which customers make multiple purchases and are willing to trade off quantity and quality. ${ }^{2}$

The form of consumer utility that underpins this paper's analysis is different, yet arguably more plausible, than that usually assumed in the unit demand literature. In particular, it is assumed that an increase in quality increases the utility gained from each unit consumed. In this way utility is a function of the product of the number of units consumed and "satisfaction per unit". ${ }^{3}$ Satisfaction per unit (as the name implies) represents the enjoyment the customer gain from consuming a unit of the product, and is assumed to be a function of quality alone. Importantly, the specification allows the substitutability of quality for quantity for each consumer to be defined. This representation of preferences is often realistic. Many, if not most, goods have the property that consumer benefit is related to the overall pleasure gained from consumption rather than the quality per unit alone or number of units alone. For example, the utility gained from consuming coffee is the product of the number of cups and the quality of each cup.

This specification of consumer preferences enables the common sources of customer heterogeneity to be captured within the economics model. Customers differ in their demand for quality for two reasons: differences in their taste for quality and differences in the cost of time taken to consumer a unit of the product. Differences in the taste for quality arise because substitutability of quality for quantity differs across consumers. Customers also differ in the time cost of consuming one unit. For example, consumers with a relatively high hourly wage have a relatively high time cost of consuming each cup of coffee. This high time cost induces high wage customers to demand a high quality, and also inhibits substitution of quantity for quality. To capture these two sources of heterogeneity, customers are divided into 'types': customers within a type have a common substitutability of quality for quantity and a time cost per unit. The model allows demand elasticities to vary across customer within a type. The type's elasticity of demand is the weighted sum of the individual customers' elasticities of demand within the type. The differences in the elasticity across customer types are shown to be an important determinant of manner in which quality is skewed.

\footnotetext{
2 The unit demand model can be shoehorned into modelling downward sloping demand curves by assuming as set of customers with a distribution of willingness to pay. However this approach clearly has its limits. This is seen clearly by the importance of the role of customers' elasticity of demand in the analysis of this paper.

${ }^{3}$ Some early work adopted the (implicit) assumption that utility arose from the product of number of units and quality per unit, notably Levhari and Peles (1973) and Kihlstrom and Levhari (1977). These analyses assumed all customers were homogenous in preferences.
} 
The paper also uses a novel method of assessing the influence of the firm's market power on quality. When quality is endogenous the firm must balance the quantity with the quantity it produces. This paper utilizes a definition of 'quality skewing', which provides a method to assess the degree that the monopolist's affects the balance of quantity and quality in order to raise revenue. The extent and manner in which the monopolist skews quality is shown to be related to the characteristics of the demand of each customer type.

The model could be applied to some industries that are natural monopolies. Prominent examples of such industries include many public utilities and government business enterprises such as parks, electricity, public transport, water supply, and telecommunications. A classic textbook question when discussing such industries is how they can be operated most efficiently while still generating sufficient revenue to cover costs. In the context of this papers analysis, it is of interest to analyse how the need to efficiently satisfy the profit constraint influences the balance of quality and quantity. The model is formulated so as to identify the social welfare maximising quantity and quality levels when the firm is constraint to satisfy a profit constraint. Thus the constrained efficient quantity and quality, together with the profit maximising quantity and quality are identified.

Section 1 of the paper describes consumer demand. Section 2 presents the case in which the firm can use third degree price discrimination. Section 3 considers the case where the firm is constrained to use uniform pricing. Section 4 presents an example of the model using iso-elastic functional forms. Section 5 concludes the paper. 


\section{Consumers and their demand}

The firm can set the quality of the product under consideration along a continuum y. Assume the firm's consumers are divided into n types. To capture differences in substitutability of quality and quantity (units) amongst customer types, let customer $\mathrm{j}$, who is a member of type i (customer ij), measure their 'satisfaction' of consuming the product, $\mathrm{x}^{\mathrm{ij}}$, using the relationship $\mathrm{x}^{\mathrm{ij}}=\mathrm{X}^{\mathrm{ij}} \mathrm{g}^{\mathrm{i}}(\mathrm{y})$. Call $\mathrm{g}^{\mathrm{i}}(\mathrm{y})$ the satisfaction per unit of type i. The elasticity of this customer's “iso-satisfaction curve”, $\mathrm{dx}^{\mathrm{ij}}=0$, is:

$$
\frac{y d X^{i j}}{X^{i j} d y}=-\varepsilon_{g y}^{i}(y)
$$

where $\varepsilon_{g y}^{\mathrm{i}} \equiv \mathrm{yg}^{\mathrm{i}}(\mathrm{y}) / \mathrm{g}^{\mathrm{i}}(\mathrm{y}), \mathrm{i}=1,2, . ., \mathrm{n}$, be the elasticity of i’s satisfaction per unit with respect to quality. By (1) $\varepsilon_{\mathrm{gy}}^{\mathrm{i}}(\mathrm{y})$ also measures the substitutability of quality for quantity. Note this substitutability depends only on customer type. Assuming that $\mathrm{g}^{\mathrm{i} \prime \prime}(\mathrm{y})<0$ ensures that the customer's indifference curves are convex.

The utility function of customer ij is $\mathrm{U}^{\mathrm{ij}}\left(\mathrm{g}^{\mathrm{i}}(\mathrm{y}) \mathrm{X}^{\mathrm{ij}}, \mathrm{L}^{\mathrm{ij}}\right)$, where $\mathrm{L}^{\mathrm{ij}}$ is the leisure of the customer. Consumption of the each unit takes (non-leisure) time of $\mathrm{a}^{\mathrm{i}} \geq 0$ hours. This imposes a "time cost" on customers for each unit consumed, and limits the customer's willingness to substitute quality for quantity. It is shown below that it is necessary that $\mathrm{a}^{\mathrm{i}}$ is non-zero if customer type i's income is to affect quality. Each consumer has of T hours available. Consumer ij's budget constraint is thus:

$$
P^{i} X^{i j}=w^{i}\left(T-L^{i j}-a^{i} X^{i j}\right)
$$

where $\mathrm{P}^{\mathrm{i}}$ is the price of per unit charge to type i customers and $\mathrm{w}^{\mathrm{i}}$ is the hourly wage rate of type i customers. The customer ij's maximisation function is:

$$
\operatorname{Max} U^{i j}\left(g^{i}(y) X^{i j}, L^{i j}\right) \text { subject to: }\left(\frac{P^{i}+a^{i} w^{i}}{g^{i}(y)}\right) g^{i}(y) X^{i j}+w^{i} L^{i j}=w^{i} T
$$

The price of satisfaction to customer $i j, p^{i}$, is defined as $p^{i} \equiv\left(P^{i}+a^{i} w^{i}\right) / g^{i}(y)$. Call $a^{i} w^{i}$ type $i$ consumers' time cost per unit. Consumer ij’s optimisation problem may be written as: 


$$
\operatorname{Max} U^{i j}\left(x^{i j}, L^{i j}\right) \text { subject to } p^{i} x^{i j} / w^{i}+L^{i j}=T
$$

where $\mathrm{x}^{\mathrm{ij}}=\mathrm{g}^{\mathrm{i}}\left(\mathrm{y}^{\mathrm{i}}\right) \mathrm{X}^{\mathrm{ij}}$ is the satisfaction provided to the customer from consumption of the product.

It is natural to consider the consumer problem in the formulation (4) rather than (3). In the formulation (4), satisfaction is the "good" which the consumer must forgo to consume leisure. All type i customers face the common price and wage $\mathrm{p}^{\mathrm{i}}$ and $\mathrm{w}^{\mathrm{i}}$. Thus standard consumer theory can be used to determine the demand for satisfaction and demand for units from type i customers as:

$$
x^{i}\left(p^{i} / w^{i}\right)=\sum_{j=1}^{m^{i}} x^{i j}\left(p^{i} / w^{i}\right) \Leftrightarrow X^{i}\left(P^{i}, g^{i}(y), w^{i}\right)=\sum_{i=1}^{m^{i}} \frac{x^{i j}\left(\frac{P^{i}+a^{i} w^{i}}{w^{i} g^{i}(y)}\right)}{g^{i}(y)}
$$

where reference to $\mathrm{T}$ is suppressed as it is common to all customer types. Type i's elasticity of demand is given by:

$$
\varepsilon_{x}^{i}\left(p^{i} / w^{i}\right) \equiv-\left(p^{i} / x^{i}\right)\left(\partial x^{i} \partial p^{i}\right)=-\left(p^{i} / w^{i} x^{i}\right) \cdot x_{1}^{i}\left(p^{i} / w^{i}\right)=\left(\left(P^{i}+a^{i} w^{i}\right) / P^{i}\right) E_{X}^{i}
$$

where $\mathrm{E}_{\mathrm{X}}^{\mathrm{i}} \equiv-\left(\mathrm{P}^{\mathrm{i}} / \mathrm{X}^{\mathrm{i}}\right)\left(\partial \mathrm{X}^{\mathrm{i}} / \partial \mathrm{P}^{\mathrm{i}}\right)$ is called the 'ordinary elasticity of demand' for type i customers. Each consumer, $\mathrm{j}$, of type i has an elasticity of demand that is defined analogously to (6), and these elasticities may differ across consumers of type i. The elasticity, $\varepsilon_{x}^{i}$, is the weighted sum of the individual type i consumers' elasticities of demand. The ordinary elasticity of demand is the measure of demand elasticity that is typically estimated in empirical studies, however it is $\varepsilon_{\mathrm{x}}^{\mathrm{i}}$ that fully represents the preferences of consumers. Thus it is $\varepsilon_{\mathrm{x}}^{\mathrm{i}}$ that is used in the analysis below to represent the elasticity of demand of each type of consumer.

The industrial organization literature generally formulates its analysis using consumer surplus and consumer benefit rather than consumer utility. For consistency with this approach, and also for ease of analysis, this approach is adopted in this paper. Integrating 
consumer i's demand curve yields their consumer surplus ${ }^{4}, v^{i}\left(p^{i}\right)$, where $v^{i}\left(p^{i}\right)=\int_{p^{i}}^{\infty} x^{i}\left(r / w^{i}\right) d r$. Note that (5) may be inverted to yield $\mathrm{p}^{\mathrm{i}}\left(\mathrm{x}^{\mathrm{i}}\right)$.

It is instructive to compare the specification of consumer preferences with that in related literature. Spence (1975) and Sheshinksi (1976) implicitly assume a representative consumer, whose demand is an arbitrary function of the number of units consumed and quality. Even with homogenous consumer preferences, it is difficult to draw general conclusions and make analytic progress with such a general specification of utility. Consequently most previous work on heterogeneity assumes, following Mussa and Rosen (1978), that the indirect utility function is given by $U=\theta q-P+I$, where $\theta$ is a taste parameter, $\mathrm{q}$ is quality, $\mathrm{P}$ is price per unit and I is utility from consumption of all other goods. Each consumer buys only one unit, and the willingness to pay for that unit varies with taste (and income). While this form of the utility function provides considerable analytical convenience, it is highly restrictive. It is based on a cardinal rather than ordinal utility function, does not allow substitution possibilities between quality and quantity, and the assumed elasticity of consumer demand is very special indeed. For the majority of goods, like those discussed in the introduction, quantity demanded by each customer varies with the price and quality of the good. 


\section{Third Degree Price Discrimination}

Under third degree price discrimination the firm can identify members of each group of customers. A distinct price per unit, $\mathrm{P}^{\mathrm{i}}$, is charged to members of group. The firm's technology is summarised by the cost function $\mathrm{C}(\mathrm{X}, \mathrm{y})$, where $\mathrm{X} \equiv \sum_{\mathrm{i}=1}^{\mathrm{n}} \mathrm{X}^{\mathrm{i}}$ is total quantity. It is assumed that marginal cost of quantity (units produced), and the marginal cost of quality are non-negative, i.e. $C_{j}(X, y) \geq 0$ for $j=1,2$. The profit of the firm, $\pi\left(p^{1}, \ldots, p^{n}, y\right)$, is:

$$
\pi\left(p^{1}, \ldots, p^{n}, y\right)=\sum_{i=1}^{n} p^{i} x^{i}\left(p^{i}\right)-f\left(x^{1}\left(p^{1}\right), . ., x^{n}\left(p^{n}\right), y\right)
$$

where $f\left(x^{1}, . ., x^{n}, y\right) \equiv F\left(x^{1} / g^{1}(y), \ldots, x^{n} / g^{n}(y), y\right)$ where:

$$
F\left(X^{1}, . ., X^{n}, y\right)=C\left(X^{1}+. .+X^{n}, y\right)+\sum_{i=1}^{n} a^{i} w^{i} X^{i}
$$

The $\mathrm{F}\left(\mathrm{X}^{1}, \ldots, \mathrm{X}^{\mathrm{n}}, \mathrm{y}\right)$ represents total cost (i.e. production cost plus the total time cost). It is useful to interpret $\mathrm{f}\left(\mathrm{x}^{1}, . ., \mathrm{x}^{\mathrm{n}}, \mathrm{y}\right)$ as the total cost of providing satisfaction $\mathrm{x}^{1} \ldots \mathrm{x}^{\mathrm{n}}$ to the respective customers as a function of quality. The surplus from production of the good is given by:

$$
\mathrm{s}\left(\mathrm{p}^{1}, \ldots, \mathrm{p}^{\mathrm{n}}, \mathrm{y}\right)=\sum_{\mathrm{i}=1}^{\mathrm{n}} \mathrm{v}^{\mathrm{i}}\left(\mathrm{p}^{\mathrm{i}}\right)+\pi\left(\mathrm{p}^{1}, \ldots, \mathrm{p}^{\mathrm{n}}, \mathrm{y}\right)
$$

The social welfare maximising firm that is required to satisfy a profit constraint $\pi\left(\mathrm{p}^{1}, \ldots, \mathrm{p}^{\mathrm{n}}, \mathrm{y}\right) \leq \bar{\pi}$. The firm's optimisation problem is thus:

$$
\max _{\mathrm{p}^{1} \ldots \mathrm{p}^{\mathrm{n}} \mathrm{y}} \mathrm{s}\left(\mathrm{p}^{1}, \ldots, \mathrm{p}^{\mathrm{n}}, \mathrm{y}\right) \text { s.t. } \pi\left(\mathrm{p}^{1}, \ldots, \mathrm{p}^{\mathrm{n}}, \mathrm{y}\right) \geq \bar{\pi}
$$


The Lagrangian for this optimisation problem is:

$$
L\left(\mathrm{p}^{1}, \ldots, \mathrm{p}^{\mathrm{n}}, \mathrm{y}\right)=\sum_{\mathrm{i}=1}^{\mathrm{n}} \mathrm{v}^{\mathrm{i}}\left(\mathrm{p}^{\mathrm{i}}\right)+(1+\lambda)\left[\sum_{\mathrm{i}=1}^{\mathrm{n}} \mathrm{p}^{\mathrm{i}} \mathrm{x}^{\mathrm{i}}\left(\mathrm{p}^{\mathrm{i}}\right)-\mathrm{f}\left(\mathrm{x}^{1}\left(\mathrm{p}^{1}\right), . ., \mathrm{x}^{\mathrm{n}}\left(\mathrm{p}^{\mathrm{n}}\right), \mathrm{y}\right)\right]-\lambda \bar{\pi}
$$

where $\lambda$ is the Lagrange multiplier. Note that the formulation (11) captures two important special cases: (i) profit maximising monopoly $(\lambda \rightarrow \infty)$ and (ii) the unconstrained efficient outcome $(\lambda=0)$. The first order condition $\partial L / \partial \mathrm{p}^{\mathrm{i}}=0$ yields:

$$
\frac{\mathrm{p}^{\mathrm{i}}-\mathrm{f}_{\mathrm{i}}\left(\mathrm{x}^{1}, \ldots, \mathrm{x}^{\mathrm{n}}, \mathrm{y}\right)}{\mathrm{p}^{\mathrm{i}}}=\left(\frac{\lambda}{1+\lambda}\right) \frac{1}{\varepsilon_{\mathrm{x}}^{\mathrm{i}}} \Leftrightarrow \frac{\mathrm{P}^{\mathrm{i}}-\mathrm{C}_{1}(\mathrm{X}, \mathrm{y})}{\mathrm{P}^{\mathrm{i}}}=\left(\frac{\lambda}{1+\lambda}\right) \frac{1}{\mathrm{E}_{\mathrm{x}}^{\mathrm{i}}}
$$

This is the familiar Lerner/Ramsey pricing rule. The first order condition $\partial L / \partial y=0$ yields:

$$
\hat{y}\left(x^{1}, \ldots, x^{n}\right)=\underset{y}{\operatorname{argmin}} f\left(x^{1}, \ldots, x^{n}, y\right)
$$

The quality level $y$ represents the 'cost minimising quality level'. There exists a cost minimizing level of quality because an increase in quality has two effects on cost, which can be identified by differentiating (8) to give:

$$
f_{n+1}\left(x^{1}, . ., x^{n}, y\right)=C_{2}\left(X^{1}+\ldots+X^{n}, y\right)-\sum_{i=1}^{n}\left[a^{i} w^{i}+C_{1}\left(X^{1}+\ldots+X^{n}, y\right)\right] X^{i} \frac{g^{i}(y)}{g^{i}(y)}
$$

The first effect is the direct cost of producing increased quality is given by the first term on the RHS of (14). The second effect, given by the second term on the RHS of (14), is that the quantity required to produce a given level of satisfaction is reduced, thereby reducing cost. Cost is minimized at the quality where the former effect just outweighs the latter effect. Hence:

Proposition 1: Under third degree price discrimination the monopolist chooses satisfaction and units according to the Lerner/Ramsey condition, (12), while quality is cost minimising, i.e. satisfies (13). 
The first order conditions of the constrained optimisation problem (10) yield, as a special case, both the monopoly and (unconstrained) efficient outcomes. When the profit constraint is not binding $(\lambda=0)$, equation (12) shows that (unconstrained) efficiency requires both types to pay the same price per unit, which is equal marginal cost. However, because both types value quality differently, they pay different prices of satisfaction. The monopoly level of $\mathrm{p}^{\mathrm{i}}$ is given by (12) when $\lambda=\infty$. As is usual with price discrimination, the type with the higher elasticity of demand pays a lower price per unit. If the type with higher elasticity of demand also places a low value on quality per unit, then this group faces a higher price of satisfaction than the other group. However, if this is not the case, the relative size of the price of satisfaction between the groups is ambiguous.

Quality is said to be skewed if it is possible to substitute quantity for quality, or visa versa, and raise the surplus. In particular skewed quality is defined as follows:

Definition 1: In a market equilibrium quality is said to be downwardly (un-, upwardly) skewed if the social marginal rate of substitution (MRS) of quality for quality is less than (equal to, greater than) the marginal rate of transformation (MRT) of quality for quality.

For the monopolist, quality can become skewed when, in order to raise revenue, the firm does not combine quality and quantity 'efficiently'.

In the case of third degree price discrimination, quality is downwardly (un-, upwardly) skewed with respect to type i’s quantity if:

$$
\frac{\mathrm{S}_{\mathrm{n}+1}\left(\mathrm{X}^{1}, . ., \mathrm{X}^{\mathrm{n}}, \mathrm{y}\right)}{\mathrm{S}_{\mathrm{i}}\left(\mathrm{X}^{1}, . ., \mathrm{X}^{\mathrm{n}}, \mathrm{y}\right)}>(=,<) \frac{\mathrm{F}_{\mathrm{n}+1}\left(\mathrm{X}^{1}, . ., \mathrm{X}^{\mathrm{n}}, \mathrm{y}\right)}{\mathrm{F}_{\mathrm{i}}\left(\mathrm{X}^{1}, . ., \mathrm{X}^{\mathrm{n}}, \mathrm{y}\right)}
$$

where $S\left(X^{1}, . ., X^{n}, y\right) \equiv s\left(p^{1}\left(g^{1}(y) X^{1}\right), \ldots, p^{n}\left(g^{n}(y) X^{n}\right), y\right)$ and thus the LHS of $(15)$ is the social MRS of quality for type i's quantity and the RHS of (15) is the MRT of quality for type i's quantity. The motivation for this definition is the observation that the unskewed combination of quantity and quality maximizes the surplus for a given level of resources devoted to production. It is thus not possible to raise the surplus by substituting quality for quantity or visa versa. Define:

$$
Z^{i}\left(X^{1}, . ., X^{n}, y\right) \equiv C_{2}\left(X^{1}+. .+X^{n}, y\right)-\left(\frac{S_{n+1}\left(X^{1}, . ., X^{n}, y\right)}{S_{i}\left(X^{1}, . ., X^{n}, y\right)}\right)\left[C_{1}\left(X^{1}+. .+X^{n}, y\right)+a^{i} w^{i}\right]
$$


In the case of third degree price discrimination, quality is downwardly (un-, upwardly) skewed with respect to type i’s quantity if $Z^{i}<(=,>) 0$.

$$
Z^{i}=\sum_{j=1}^{n}\left(C_{1}+a^{j} w^{j}\right)\left[\frac{\varepsilon_{x}^{j}-\varepsilon_{x}^{i}}{\varepsilon_{x}^{i}\left(\varepsilon_{x}^{j}-1\right)}\right] X^{i} \varepsilon_{g y}^{j}
$$

Thus:

Proposition 2: Under third degree price discrimination quality is downwardly (un-, upwardly) skewed with respect to type i's quantity if, in equilibrium, the elasticity of demand of type i consumers is less than (equal to, more than) the elasticity of demand of all other types of consumers.

If type $\mathrm{i}$ has the lowest elasticity of demand in equilibrium, it is possible to increase the surplus by substituting quantity for quantity.

The monopolist's production decision can be conceptually decomposed into two steps: (i) the monopolist restricts "output” $\left(\mathrm{X}^{\mathrm{i}}\right.$ or $\left.\mathrm{x}^{\mathrm{i}}\right)$ provided to type i customers to increase profits in the manner described in textbooks, and (ii) the monopolist chooses the balance of output and quality to maximize profits. The former action is represented by movements along the contract curve, while the latter is the skewness (which is represented by movements away from the contract curve). The impact of these actions on quality is ambiguous: it depends on the slope of the contract curve and the direction of skewness. Thus equilibrium quality may either be above or below the efficient level.

It is also possible to consider the quality being skewed with respect to the satisfaction provided to type i customers. In particular, quality is downwardly (un-, upwardly) skewed with respect to the satisfaction of type i customer if $z^{i}<(=,>) 0$, where:

$$
z^{i}\left(x^{1}, . ., x^{n}, y\right) \equiv f_{n+1}\left(x^{1}, . ., x^{n}, y\right)-\left(\frac{\sigma_{n+1}\left(x^{1}, . ., x^{n}, y\right)}{\sigma_{i}\left(x^{1}, . ., x^{n}, y\right)}\right) f_{i}\left(x^{1}, . ., x^{n}, y\right)
$$

where $\sigma\left(\mathrm{x}^{1}, \ldots, \mathrm{x}^{\mathrm{n}}, \mathrm{y}\right) \equiv \mathrm{s}\left(\mathrm{p}^{1}\left(\mathrm{x}^{1}\right), \ldots, \mathrm{p}^{\mathrm{n}}\left(\mathrm{x}^{\mathrm{n}}\right), \mathrm{y}\right)$. In equilibrium under third degree price discrimination $\mathrm{z}^{\mathrm{i}}=0$, hence quality is not skewed with respect to satisfaction of any of the consumer types. 


\section{Common price per unit}

Suppose the firm must apply a price per unit that is common to all customers. In this case the surplus may be written:

$$
\mathrm{S}(\mathrm{P}, \mathrm{y})=\mathrm{V}(\mathrm{P}, \mathrm{y})+\pi(\mathrm{P}, \mathrm{y})
$$

where consumer surplus is given by $\mathrm{V}(\mathrm{P}, \mathrm{y})=\sum_{\mathrm{i}=1}^{\mathrm{n}} \mathrm{v}^{\mathrm{i}}\left(\left(\mathrm{P}+\mathrm{a}^{\mathrm{i}} \mathrm{w}^{\mathrm{i}}\right) / \mathrm{g}^{\mathrm{i}}\right)$ and profit is given by:

$$
\left.\pi(P, y)=P \sum_{i=1}^{n} x^{i}\left(\left(P+a^{i} w^{i}\right) / g^{i}\right) / g^{i}-C\left(\left[x^{1}\left(\left(P+a^{i} w^{i}\right) / g^{1}\right) / g^{1}+. .+x^{n}\left(P+a^{i} w^{i}\right) / g^{n}\right) / g^{n}\right], y\right)
$$

The firm's optimisation problem with a common price per unit is:

$$
\max _{\mathrm{P} y} \mathrm{~S}(\mathrm{P}, \mathrm{y}) \text { s.t. } \pi(\mathrm{P}, \mathrm{y}) \leq \bar{\pi}
$$

In this case Ramsey pricing is equivalent to average cost pricing, though average cost is determined by the quality level chosen. The Lagrangian for the optimisation problem (21) is:

$$
\begin{aligned}
L(\mathrm{P}, \mathrm{y}, \lambda) & =\mathrm{V}(\mathrm{P}, \mathrm{y})+\pi(\mathrm{P}, \mathrm{y})+\lambda(\pi(\mathrm{P}, \mathrm{y})-\bar{\pi}) \\
& \left.=\sum_{\mathrm{i}=1}^{\mathrm{n}} \mathrm{v}^{\mathrm{i}}\left(\mathrm{P}+\mathrm{a}^{\mathrm{i}} \mathrm{w}^{\mathrm{i}}\right) / \mathrm{g}^{\mathrm{i}}\right)-\lambda \bar{\pi} \\
& \left.\left.+(1+\lambda)\left[\mathrm{P} \sum_{\mathrm{i}=1}^{\mathrm{n}} \mathrm{x}^{\mathrm{i}}\left(\left(\mathrm{P}+\mathrm{a}^{\mathrm{i}} \mathrm{w}^{\mathrm{i}}\right) / \mathrm{g}^{\mathrm{i}}\right) / \mathrm{g}^{\mathrm{i}}-\mathrm{C}\left(\left[\mathrm{x}^{1}\left(\mathrm{P}+\mathrm{a}^{\mathrm{i}} \mathrm{w}^{\mathrm{i}}\right) / \mathrm{g}^{1}\right) / \mathrm{g}^{1}+. .+\mathrm{x}^{\mathrm{n}}\left(\mathrm{P}+\mathrm{a}^{\mathrm{i}} \mathrm{w}^{\mathrm{i}}\right) / \mathrm{g}^{\mathrm{n}}\right) / \mathrm{g}^{\mathrm{n}}\right], \mathrm{y}\right)\right](22)
\end{aligned}
$$

The first order condition $\partial \mathrm{L} / \partial \mathrm{P}=0$ yields the familiar Ramsey condition:

$$
\frac{\mathrm{P}-\mathrm{C}_{1}}{\mathrm{P}}=\left(\frac{\lambda}{1+\lambda}\right) \frac{1}{\mathrm{E}_{\mathrm{x}}}
$$


where $E_{x}=\sum_{i=1}^{n}\left[X^{i} E_{x}^{i}\right] / X$ is elasticity of the total demand curve. Eliminating $\lambda$ from the first order condition $\partial L / \partial \mathrm{P}=0$ and $\partial L / \partial \mathrm{y}=0$ yields:

$$
f_{n+1}\left(x^{1}, \ldots, x^{n}, y\right)=\left(\frac{P-C_{1}}{y X ~ P}\right) \sum_{i=1}^{n-1} \sum_{j=i+1}^{n} X^{i} X^{j}\left(E_{X}^{i}-E_{X}^{j}\right)\left[\left(P+a^{i} w^{i}\right) \varepsilon_{g y}^{i}-\left(P+a^{j} w^{j}\right) \varepsilon_{g y}^{j}\right]
$$

where the RHS of (24) may be interpreted as the 'rate of return constrained' marginal revenue of quality. Equilibrium quality is above (equal, below) the cost minimising level if $\mathrm{f}_{\mathrm{n}+1}>(=,<) 0$. $^{5}$

It is of interest to determine how the profit maximising monopolist skews quality when it must set a common price per unit. The monopolist's quality and quantity choice is depicted in figure 1 . The monopolist maximises profit at the point $\Pi^{\mathrm{m}}$, where the iso-totalrevenue curve, $\mathrm{R}^{\mathrm{m}}=\sum_{\mathrm{i}=1}^{\mathrm{n}}\left(\mathrm{P}+\mathrm{a}^{\mathrm{i}} \mathrm{w}^{\mathrm{i}}\right) \mathrm{X}^{\mathrm{i}}$, is tangent to the iso-total-cost curve $\mathrm{F}^{\mathrm{m}}$. Quality is unskewed at the point $\Pi^{\mathrm{m}}$, where the indifference curve $\mathrm{V}^{\mathrm{u}}$ is tangent to $\mathrm{F}^{\mathrm{m}}$, the iso-total-cost curve. That is, quality is unskewed when the quantity-quality combination is $\left(\mathrm{X}^{\mathrm{u}}, \mathrm{y}^{\mathrm{u}}\right)$. Note that figure 1 is drawn is drawn so that at the point chosen by the profit maximising monopolist, $\Pi^{\mathrm{m}}$, quality is downwardly skewed, as the MRS $<$ MRT. The difference between the efficient levels of quantity and quality $\left(\mathrm{X}^{\mathrm{e}}, \mathrm{y}^{\mathrm{e}}\right)$, and profit maximising levels of quantity and quality $\left(\mathrm{X}^{\mathrm{m}}, \mathrm{y}^{\mathrm{m}}\right)$ can thus be decomposed into two parts. The component between $\left(\mathrm{X}^{\mathrm{e}}, \mathrm{y}^{\mathrm{e}}\right)$ and $\left(\mathrm{X}^{\mathrm{u}}, \mathrm{y}^{\mathrm{u}}\right)$ is the unskewed component while the $\left(\mathrm{X}^{\mathrm{u}}, \mathrm{y}^{\mathrm{u}}\right)$ and $\left(\mathrm{X}^{\mathrm{m}}, \mathrm{y}^{\mathrm{m}}\right)$ is the skewed component.

To identify the direction of skewness define:

$$
\mathrm{Z}(\mathrm{X}, \mathrm{y}) \equiv \mathrm{F}_{2}(\mathrm{X}, \mathrm{y})-\left(\frac{\mathrm{S}_{2}(\mathrm{X}, \mathrm{y})}{\mathrm{S}_{1}(\mathrm{X}, \mathrm{y})}\right) \mathrm{F}_{1}(\mathrm{X}, \mathrm{y})
$$

\footnotetext{
${ }^{5}$ In the analysis of Levhari and Peles (1973) and Kihlstrom and Levhari (1977) all customers are homogenous (the elasticity of satisfaction with respect to quality is one for all customers and all customers have a common elasticity of demand) and $\mathrm{a}^{\mathrm{i}}$ is zero for all customer types. Thus firms produce the cost minimising level of quality.
} 
The locus of unskewed quantity and quality is the contract curve, i.e the sets (X,y) where the social indifference curve is tangent to the iso-(total) cost curve (so that $\mathrm{Z}(\mathrm{X}, \mathrm{y})=0$ ). The contract curve is implicitly given by the equation:

$$
\begin{aligned}
& f_{n+1}\left(g^{1}(y) X^{1}, \ldots, g^{n}(y) X^{n}, y\right) \\
& =\left(\frac{\left(P-C_{1}\right)}{y X P \varepsilon_{x}}\right) \sum_{i=1}^{n-1} \sum_{j=i+1}^{n} X^{i} X^{j} E_{x}^{i} E_{x}^{j}\left(a^{i} w^{i}-a^{j} w^{j}\right)\left[\left(P+a^{i} w^{i}\right) \varepsilon_{g y}^{i}-\left(P+a^{j} w^{j}\right) \varepsilon_{g y}^{j}\right](26)
\end{aligned}
$$

It is apparent from (26) that when customer types have a common time cost per unit then the contract curve coincides with the cost minimising curve. When, however there is a homogenous taste for quality, but some heterogeneity in time cost per unit, the contract curve lies above the cost minimising curve.

In equilibrium, the direction of skewness is given by:

$$
Z(X, y)=\left(\frac{\left(P-C_{1}\right) E_{x}}{y X P \varepsilon_{x}}\right) \sum_{i=1}^{n-1} \sum_{j=i+1}^{n} X^{i} X^{j}\left(\varepsilon_{x}^{i}-\varepsilon_{x}^{j}\right)\left[\left(P+a^{i} w^{i}\right) \varepsilon_{g y}^{i}-\left(P+a^{j} w^{j}\right) \varepsilon_{g y}^{j}\right]
$$

In the case of uniform pricing, quality is downwardly (un-,upwardly) skewed with respect to type i’s quantity if $\mathrm{Z}(\mathrm{X}, \mathrm{y})<(=,>) 0$.

By inspection of (24) and (27), it is apparent that the direction of skewness of equilibrium quality will correspond with its direction away from the cost minimising level (i.e. $f_{n+1}$ and $Z$ are equal) when all types have a common time cost per unit, $\left(a^{i} w^{i}=a^{j} w^{j}\right.$ for all $\mathrm{i}, \mathrm{j})$. In general this need not be the case. However to help identify those cases in which this relationship does hold the following definition is useful.

Definition 2: (i) Customers have (uniformly, inversely) ordered taste and elasticity if, for all $\mathrm{i}, \mathrm{j}, \varepsilon_{\mathrm{gy}}^{\mathrm{i}}>\varepsilon_{\mathrm{gy}}^{\mathrm{j}}, \varepsilon_{\mathrm{x}}^{\mathrm{i}}>(=,<) \varepsilon_{\mathrm{x}}^{\mathrm{j}}, \mathrm{a}^{\mathrm{i}} \mathrm{w}^{\mathrm{i}}=\mathrm{a}^{\mathrm{j}} \mathrm{w}^{\mathrm{j}}$. (ii) Customers have (uniformly, inversely) ordered time cost per unit and elasticity if, for all $\mathrm{i}, \mathrm{j}, \mathrm{a}^{\mathrm{i}} \mathrm{w}^{\mathrm{i}}>\mathrm{a}^{\mathrm{j}} \mathrm{w}^{\mathrm{j}}, \varepsilon_{\mathrm{x}}^{\mathrm{i}}>(=,<) \varepsilon_{\mathrm{x}}^{\mathrm{j}}, \varepsilon_{\mathrm{gy}}^{\mathrm{i}}=\varepsilon_{\mathrm{gy}}^{\mathrm{l}}$. Without loss of generality the types can be ordered so that the elasticity of satisfaction per unit with respect to quality or the time cost of income decreases with the index, i. 
Consequently, using definition 2:

Proposition 3: Suppose the monopolist sets a common price per unit for all customers.

(a) The monopolist sets the cost minimising quality and quality is unskewed if:

(i) the profit constraint is not binding $(\lambda=0)$, or

(ii) Customer types have a common time cost per unit, $\left(a^{i} w^{i}=a^{j} w^{j}\right.$ for all $\mathrm{i}, \mathrm{j})$ and a homogenous taste for quality $\left(\varepsilon_{\mathrm{gy}}^{\mathrm{i}}=\varepsilon_{\mathrm{gy}}^{\mathrm{j}}\right.$ for all $\left.\mathrm{i}, \mathrm{j}\right)$, or

(iii) Customers have a common elasticity of demand $\left(\varepsilon_{\mathrm{x}}^{\mathrm{i}}=\varepsilon_{\mathrm{x}}^{\mathrm{j}}\right.$ for all $\left.\mathrm{i}, \mathrm{j}\right)$.

(b) Quality is greater (less) than the cost minimising level and quality is upwardly (downwardly) skewed if customers have (inversely) ordered taste and elasticity.

(c) Quality is upwardly (downwardly) skewed if customers have (inversely) ordered time cost per unit and elasticity.

(d) Quality is below the cost minimising level if customers have uniformly ordered time cost per unit and elasticity.

As is usual (under profit maximisation or the Ramsey pricing rule), the firm maximises its benefit by lowering the relative the price of satisfaction to the group with the most elastic demand. Suppose, for example, type1 customers are the group with the most elastic demand. One way to lower the price of satisfaction is to raise quality. If, additionally, type 1 customers are more sensitive to quality changes than other types (i.e. $\varepsilon_{\mathrm{gy}}^{1}>\varepsilon_{\mathrm{gy}}^{\mathrm{j}}$ for $\mathrm{j} \neq 1$ ) then an increase in quality lowers their price of satisfaction by relative to that of the other types. Similarly, if type 1 has the highest time cost per unit, an increase in quality will lower that type's price of satisfaction more than it does other types. This means profit is increased by upwardly skewing quality. Specifically the RHS of (24), i.e. the constrained marginal revenue of quality, is positive. The monopolist's requirement to raise revenue not only leads to an inefficiently low quantity produced, but also leads (in this instance) to an upwardly skewed quality. 


\section{An Example}

In the example considered in this section it is assumed that consumers have the following constant elasticity demand function:

$$
x^{i}=A^{i} /\left(p^{i} / w^{i}\right)^{\alpha^{i}}
$$

where $A^{i}>0$ is the level of type $i$ consumer's demand and $\alpha^{i}>0$ is the elasticity of demand of type i customers. (The assumption of constant elasticity allows abstraction from the variations in demand elasticity that arises from the movement along a customer type's demand curve.)

Assume also that firms have the following 'constant returns to scale' cost function:

$$
\mathrm{C}(\mathrm{X}, \mathrm{y})=\mathrm{X} \psi(\mathrm{y})
$$

where $\psi^{\prime}(\mathrm{y})>0$ and $\psi^{\prime \prime}(\mathrm{y})>0$. For the constant returns to scale cost function, (14) implies the minimum cost quality level is given by:

$$
f_{n+1}=\sum_{i=1}^{n} x^{i} \Gamma^{i}(\hat{y})=0
$$

where $\Gamma^{\mathrm{i}}(\mathrm{y})=\frac{\mathrm{a}^{\mathrm{i}} \mathrm{w}^{\mathrm{i}}+\psi(\mathrm{y})}{\mathrm{g}^{\mathrm{i}}(\mathrm{y})}$. Define $\hat{y}^{\mathrm{i}}$ by $\Gamma^{\mathrm{i} \prime}\left(\hat{\mathrm{y}}^{\mathrm{i}}\right) \equiv 0$. Call $\hat{y}^{\mathrm{i}}$ the optimal quality for type $\mathrm{i}$ consumers. It is level of quality that would be provided to type i customer if the firm could differentiate its product. When $\hat{y}<\hat{y}$ type i's optimal quality is below the cost minimising quality level. Increasing the level satisfaction of type i increases their weighting in the calculation of the cost minimising quality. This lowers the cost minimising level of quality when $\hat{y}^{\mathrm{i}}<\hat{y}$. 
Consider first the case in which all customer types have the same elasticity of demand, $\alpha^{\mathrm{i}}=\alpha$ for all i. ${ }^{6}$ Proposition 1 and proposition 2 implies that quality is not skewed and equal to the cost minimising level under third degree price discrimination. The cost minimising quality under thirst third degree price discrimination is given implicitly by:

$$
\varepsilon_{\psi y}(y)=\frac{\sum_{i=1}^{n}\left\{A^{i}\left[a^{i} w^{i}+\psi(y) / \psi(y) g^{i}(y)\right]^{1-\alpha} \varepsilon_{g y}^{i}(y)\right\}}{\left.\sum_{i=1}^{n}\left\{\left(A^{i} / g^{i}\right)\left[a^{i} w^{i}+\psi(y) / \psi(y) g^{i}(y)\right]^{-\alpha}\right\}\right\}}
$$

Thus quality is independent of $\bar{\pi}$ (or equivalently $\lambda$ ) and Swan invariance holds. That is, the quality the monopolist chooses is the efficient level of quality (Swan 1970).

Similarly, under a common price per unit, proposition 3 implies that quality is not skewed when all customer types have a common elasticity of demand. Quality is equal to the cost minimising level if there is a heterogenous taste for quality but a common time cost per unit. The cost minimising level of quality is given implicitly by:

$$
\sum_{i=1}^{n} A^{i}\left(g^{i}(\hat{y})\right)^{\alpha} \Gamma^{i \prime}(\hat{y})=0
$$

Thus, again, quality is independent of $\bar{\pi}$ (or equivalently $\lambda$ ) and Swan invariance holds.

However if there is a heterogeneous time cost per unit, but a homogenous taste for quality, then, by proposition 3, the firm chooses quality below the cost minimising level. The cost minimising quality satisfies:

\footnotetext{
6 This assumption may be a reasonable approximation when customer types have a common distribution of demand within them. Differences across customer types then would only arise because of either taste for quality or incomes.
} 


$$
\frac{d \hat{y}}{d P}=\frac{\alpha\left(x^{n} \Gamma^{n \prime}(\hat{y})\right)}{f_{(n+1)(n+1)}}\left\{\frac{1}{P+a^{n} w^{n}}-\frac{\sum_{i=1}^{n-1}\left(x^{i} \Gamma^{i}(\hat{y}) /\left(P+a^{i} w^{i}\right)\right)}{\sum_{i=1}^{n-1} x^{i} \Gamma^{i}(\hat{y})}\right\}
$$

where $x^{n} \Gamma^{n \prime}(y)>0$ as type n's have the lowest preference for quality. In general it is not possible to unambiguously sign $d y / d P$ for $n \geq 3$. However if $n=2$ then $d y / d P>0$. In this case the cost minimising quality is below the efficient level (for $\mathrm{P}>\mathrm{C}_{1}$ ). Thus, in the $\mathrm{n}=2$ case equilibrium quality is below the efficient level.

When the elasticity of demand differs across customer types propositions 2 and 3 indicates that quality is skewed. A set of numerical simulations are used to indicate the relative impact and importance of skewing. The simulations assume two customer types and a profit maximising monopolist $(\lambda=\infty)$. In particular, it is assumed that $\alpha^{2}=1.01 \mathrm{~A}^{1}=1, \mathrm{~A}^{2}=5$, $a^{1}=a^{2}=1, w^{1}=5, w^{2}=1, \psi(y)=0.1 y^{1.5}, g^{1}(y)=y^{0.1}$ and $g^{2}(y)=y^{0.9}$. Table 1 presents the equilibrium values of the variables in the model for various values of the $\alpha^{1}$.The values of the parameters are chosen to give a clear impression of the impact on skewing. In particular the low value of type 2 customers' the elasticity of demand allows for calculations in which there is a substantial difference between $\alpha^{2}$ and $\alpha^{1}$.

In this formulation the value of the optimal quality for type 1 customers is $\hat{y}^{1}=2.34$ and the value of the optimal quality for type 2 customers is $\hat{y}^{2}=6.08$. For comparison purposes table 1 provides the price (per unit), $\mathrm{P}^{1}, \mathrm{P}^{2}$ and quality level, $\mathrm{y}^{\mathrm{t}}$, under third degree price discrimination for each of the parameter values. Note that as type 1 customers' demand becomes more elastic, the quantity they consumer increases. Thus, with the increase in their elasticity of demand, type 1 customers' preference come to dominate the setting of quality under third degree price discrimination (with these parameter values).

Table 1 reports simulations on the assumption that firms are constrained to set a common price per unit. The table shows, for each set of parameter values, the variables under the assumptions (i) quality and quantity is chosen to maximise profits (m superscript), (ii) quality is unskewed (u superscript) and (iii) quality and quantity are chosen efficient (e superscript). The unskewed values are calculated on the assumption that total cost is the same as that for the profit maximising monopoly. First observe that when $\alpha^{1}=1.01$ that (as indicated by proposition 2) the monopolist does not skew quality, thus the unskewed and profit maximising simulations coincide. Figure 1 can be used to interpret the simulations for 
$\alpha^{1}>1.01$. In particular the profit maximising monopolist downwardly skews quality $\left(\mathrm{y}^{\mathrm{m}}<\mathrm{y}^{\mathrm{u}}\right)$. However the efficient quality, $\mathrm{y}^{\mathrm{e}}$, is less than the unskewed quality. The net effect however is that the effect of skewing dominates, and quality is below the efficient level $\left(\mathrm{y}^{\mathrm{m}}<\mathrm{y}^{\mathrm{e}}\right)$.

The unskewed price (per unit), $\mathrm{P}^{\mathrm{u}}$, is higher than monopoly price, $\mathrm{P}^{\mathrm{m}}$, though recall that the unskewed quality is much higher than the monopoly quality. As quality is downwardly skewed, the unskewed quantity, $\mathrm{X}^{\mathrm{u}}$, is below $\mathrm{X}^{\mathrm{m}}$, the profit maximising level. Indeed the unskewed quantity for both types is less than monopoly quantity $\left(\mathrm{X}^{\mathrm{ui}}<\mathrm{X}^{\mathrm{mi}}\right)$.

Table 1 reports the surplus (S) and consumer surplus $\left(\mathrm{v}^{\mathrm{i}}\right)$ for both customer types. Skewing lowers the surplus (i.e. $\mathrm{S}^{\mathrm{m}}<\mathrm{S}^{\mathrm{u}}$ ), the amount increases by the difference increases with $\alpha^{1}$. In these simulations skewing contributes a substantial amount (20-30\%) to the lowering of surplus due to the exercise of monopoly power. In the simulations type 2 customers have a higher consumer surplus when quality is unskewed rather than set at the profit maximising level. The reverse is true for type 1 customers. Thus the skewing of quality by the profit maximising monopolist advantages type 2 customers and disadvantages type 1 customer. 


\begin{tabular}{|c|c|c|c|c|c|c|}
\hline \multicolumn{7}{|c|}{ Table 1} \\
\hline \multirow[t]{2}{*}{ Variable } & \multicolumn{6}{|c|}{ Value of $\alpha^{1}$} \\
\hline & 1.01 & 1.2 & 1.5 & 2 & 2.5 & 3 \\
\hline & \multicolumn{6}{|c|}{ Third degree price discrimination } \\
\hline $\mathrm{y}^{\mathrm{t}}$ & 4.64 & 2.41 & 2.41 & 2.41 & 2.41 & 2.41 \\
\hline $\mathrm{X}^{1 \mathrm{t}}$ & 0.01 & 0.11 & 0.18 & 0.24 & 0.27 & 0.29 \\
\hline $\mathrm{X}^{2 \mathrm{t}}$ & 0.02 & 0.04 & 0.04 & 0.04 & 0.04 & 0.04 \\
\hline $\mathrm{P}^{1}$ & 601 & 27.24 & 11.12 & 5.75 & 3.96 & 3.06 \\
\hline \multirow[t]{2}{*}{$\frac{\mathrm{P}^{2}}{\mathrm{P}}$} & 201 & 137.70 & 137.70 & 137.70 & 137.70 & 137.70 \\
\hline & \multicolumn{6}{|c|}{ Common price per unit } \\
\hline $\mathrm{S}^{\mathrm{m}}$ & 966 & 510 & 500 & 497 & 496 & 494 \\
\hline $\mathrm{S}^{\mathrm{u}}$ & 966 & 512 & 502 & 500 & 499 & 497 \\
\hline $\mathrm{S}^{\mathrm{e}}$ & 1003 & 528 & 513 & 508 & 507 & 506 \\
\hline $\mathrm{v}^{1 \mathrm{~m}}$ & 479 & 16.71 & 4.90 & 1.61 & 0.67 & 0.21 \\
\hline $\mathrm{v}^{1 \mathrm{u}}$ & 479 & 15.94 & 4.30 & 1.21 & 0.41 & 0.09 \\
\hline $\mathrm{v}^{1 \mathrm{e}}$ & 500 & 24.86 & 9.54 & 4.85 & 3.19 & 2.35 \\
\hline $\mathrm{v}^{2 \mathrm{~m}}$ & 478 & 485.6 & 488 & 490 & 490 & 489 \\
\hline $\mathrm{v}^{2 \mathrm{u}}$ & 478 & 488.7 & 492 & 494 & 494 & 492 \\
\hline $\mathrm{v}^{2 \mathrm{e}}$ & 503 & 503 & 503 & 503 & 503 & 503 \\
\hline $\mathrm{y}^{\mathrm{m}}$ & 6.08 & 2.12 & 1.77 & 1.58 & 1.49 & 1.47 \\
\hline $\mathrm{y}^{\mathrm{u}}$ & 6.08 & 6.48 & 6.78 & 7.06 & 7.12 & 6.78 \\
\hline $\mathrm{y}^{\mathrm{e}}$ & 4.65 & 4.65 & 4.66 & 4.67 & 4.68 & 4.70 \\
\hline $\mathrm{P}^{\mathrm{m}}$ & 450 & 35.43 & 17.05 & 11.22 & 10.11 & 12.81 \\
\hline $\mathrm{P}^{\mathrm{u}}$ & 450 & 52.23 & 27.79 & 20.22 & 19.60 & 26.21 \\
\hline$\overline{\mathrm{P}^{\mathrm{e}}}$ & 1.00 & 1.00 & 1.01 & 1.01 & 1.01 & 1.02 \\
\hline $\mathrm{X}^{\mathrm{m}}$ & 0.21 & 0.22 & 0.38 & 0.50 & 0.51 & 0.38 \\
\hline $\mathrm{X}^{\mathrm{u}}$ & 0.21 & 0.15 & 0.24 & 0.28 & 0.27 & 0.19 \\
\hline$\overline{X^{\mathrm{e}}}$ & 3.35 & 3.34 & 3.33 & 3.31 & 3.30 & 3.28 \\
\hline $\mathrm{X}^{1 \mathrm{~m}}$ & 0.11 & 0.08 & 0.11 & 0.10 & 0.07 & 0.02 \\
\hline $\mathrm{X}^{1 \mathrm{u}}$ & 0.11 & 0.06 & 0.07 & 0.05 & 0.02 & 0.01 \\
\hline $\mathrm{X}^{1 \mathrm{e}}$ & 0.83 & 0.828 & 0.82 & 0.81 & 0.80 & 0.78 \\
\hline $\mathrm{X}^{2 \mathrm{~m}}$ & 0.11 & 0.133 & 0.27 & 0.40 & 0.44 & 0.38 \\
\hline $\mathrm{X}^{2 \mathrm{u}}$ & 0.11 & 0.092 & 0.17 & 0.23 & 0.24 & 0.19 \\
\hline $\mathrm{X}^{2 \mathrm{e}}$ & 2.52 & 2.51 & 2.51 & 2.51 & 2.50 & 3.28 \\
\hline
\end{tabular}




\section{Conclusion}

This paper considers the quality of a good supplied by a monopolist whose customers may have heterogeneous taste for quality and/or time cost per unit. These differences in customer characteristics, and their impact on demand, are modelled explicitly. The firm cannot, for cost or political reasons, use varieties of differing quality to segment the market according to these characteristics. The social welfare and profit maximising quality are identified under the assumptions that (i) the firm can third degree price discriminate and (ii) the firm must set a uniform price per unit to all customers.

The balance of quality and quality of the good is assessed by determining if and how quality is skewed. The model shows that the monopolist skews quality in order to increase revenue except in a number of special cases. For instance quality is unskewed if all customers types have the same elasticity of demand. This requirement may seem too unlikely a coincidence to hold in practice but, in fact, that may not be so. Recall that the type's elasticity of demand is the average of the elasticity of demand within the type. For many goods there is no a priori reason why a particular substitutability of quality for quantity or the time cost should be systematically associated with particular elasticity of demand. If there is no such systematic relationship, then it would be expected that the average demand of each customer type will be equal. In this case, when the demand curve is relatively iso-elastic, quality will not be skewed.

For example, consider a take away coffee shop operating in the central business district of a city. The customers of this coffee shop will have a variety of income levels. However, because all are working in similar circumstances, it is conceivable that the average elasticity of demand does not vary significantly between these income groups. If this is the case the quality of the coffee would not be skewed, and the difference between the quality level chosen by the firm and the efficient level is described purely by movements along the contract curve. In this case it was shown, in section 4, that quality will be below the efficient level when the firm has a constant returns cost function and two customer types.

In contrast, consider a coffee shop (or diner) on a highway. The coffee shop's customers might be divided into locals and travellers. For the usual reasons, the locals are likely to have more elastic demand than the travellers. If either the income level or the taste for quality differs between the travellers and locals, then the quality of coffee will be skewed. 
In particular, if the income level of locals is lower than that of travellers, the quality of coffee will be downwardly skewed.

In many other cases it could be argued that there is a systematic relationship between the elasticity of demand and the customer type. Consider, for example, a public transport system. The customer of public transport could be divided into two types: commuters and casual users. Because of their relatively higher reliance on public transport, commuters are likely to have relatively inelastic demand. Because they are engaged in full time employment, commuters are also likely to have a relatively high time cost. In this case proposition 3 suggests that the quality of the public transport system will be downwardly skewed.

The analysis in this paper can be adapted to investigate closely related issues. The literature on quality choice is closely related to that on durability choice (see Waldman 2003 for a recent survey). The primary difference is that the former is usually modelled within a static framework, while the latter necessarily models dynamics of product durability. Consequently the static quality models are most readily applied to describing the determinants of the quality of non-durable goods or services. Nonetheless the model presented in this paper can act as a guide to the determinants of durability, particularly when the details of the dynamic adjustment of durability are not important.

The model presented in section 3 may also be modified to apply to government business enterprises. Such firms are often thought to act as revenue maximising subject to a non-negative profit constraint, rather than profit maximising as assumed in this paper. The modelling in this paper can be readily modified to accommodate this change in assumptions by replacing profit maximisation with revenue maximisation as the objective of the firm. It is then straightforward to show that the revenue-maximising firm skews quality in a manner similar to that described in by the model presented in this paper. 


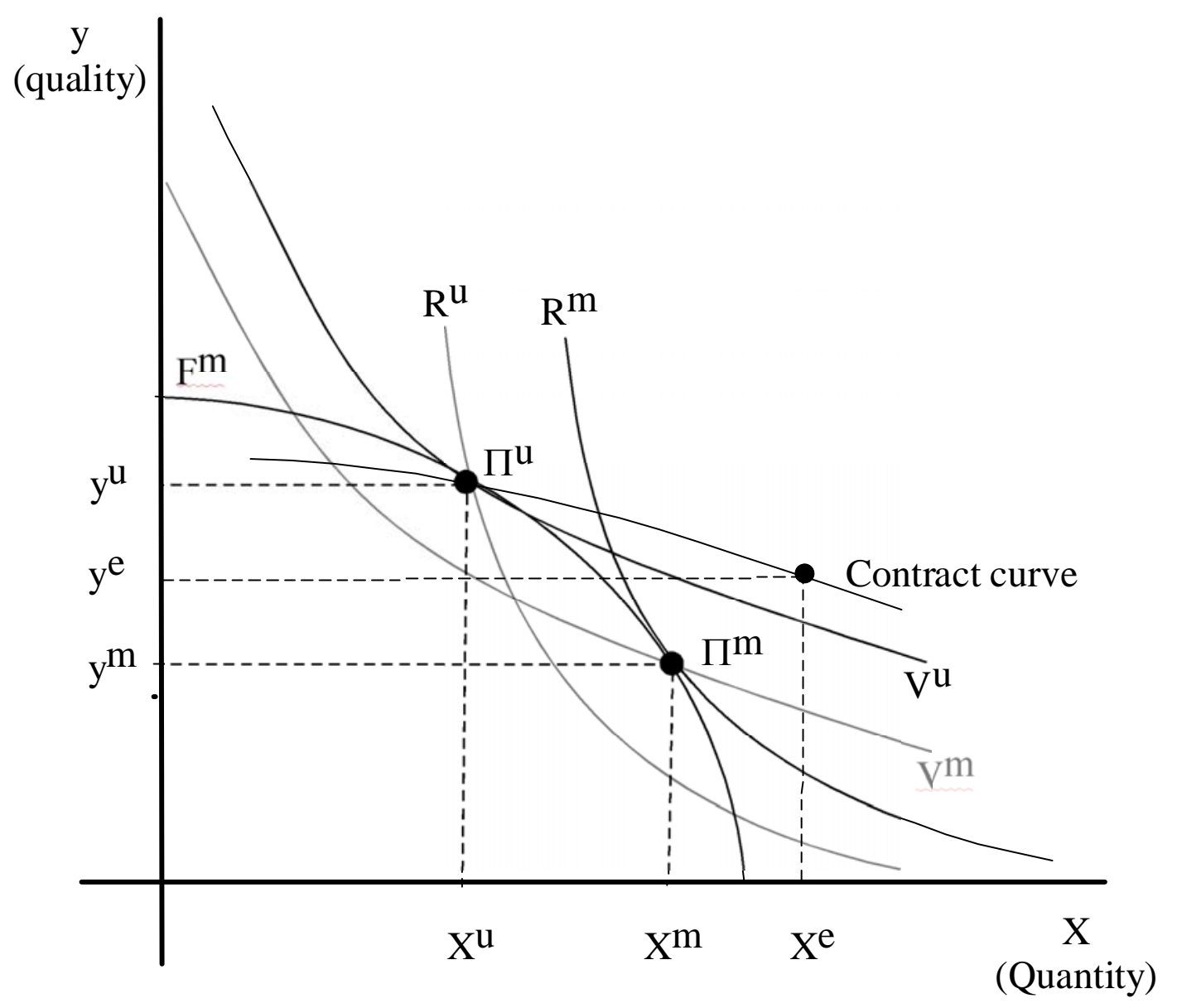

Figure 1: Quality skewness 


\section{References}

Armstrong, M. (1996), “Multiproduct nonlinear pricing”, Econometrica, 64(1), pp. 51-75.

Kihlstrom, R. E. and Levhari, D., (1977), “Quality, Regulation and Efficiency”, Kyklos, V30, pp.214-34.

Levhari, D. and Peles, Y., (1973), “Market Structure, Quality and Durability”, Bell Journal of Economics, vol. 4, no. 1, Spr. 1973, pp. 235-48

Mussa, M. and Rosen, S., (1978) “Monopoly and Product Quality”, Journal of Economic Theory, 301-17.

Sappington, D., (2005), “Regulated Service Quality: A Survey”, Journal of Regulatory Economics, 27(2), pp. 123-54.

Sheshinski, E., (1976), “Price, Quality and Quality Regulation in Monopoly Situations”, Economica, 43, pp.127-37.

Sibly, H. (2004), “Ramsey Prices and Qualities” School of Economics, University of Tasmania Discussion Paper 2004-07.

Sibley, D., and Srinagesh, P., (1997), “Multiproduct nonlinear pricing with multiple taste characteristics”, Rand Journal of Economics, 28(4), pp.684-707.

Spence, A.M. (1975) “Monopoly, quality and regulation”, Bell Journal of Economics, pp. 417-429.

Swan, P., (1970), “The durability of consumption goods”, American Economic Review, pp.884-94.

Waldman, M., (2003), “Durable Goods Theory for Real World Markets”, Journal of Economic Perspectives, Winter 17(1), pp.131-154 


\section{School of Economics and Finance Discussion Papers}

2007-01 Dietary Changes, Calorie Intake and Undernourishment: A Comparative Study of India and Vietnam, Ranjan Ray

2007-02 A Re-examination of the Real Interest Parity Condition Using Threshold Cointegration, Arusha Cooray

2007-03 Teaching Aggregate Demand and Supply Models, Graeme Wells

2007-04 Markets, Institutions and Sustainability, Ella Reeks

2007-05 Bringing Competition to Urban Water Supply, Hugh Sibly and Richard Tooth

2007-06 Changes in Indonesian Food Consumption Patterns and their Nutritional Implications, Elkana Ngwenya and

Ranjan Ray

2007-07 The Term Spread and GDP Growth in Australia, Jacob Poke and Graeme Wells

2007-08 Moving Towards the USDA Food Guide Pyramid Food: Evidence from Household Food Group Choice in Vietnam, Elkana Ngwenya

2007-09 The Determinants of the Quantity-Quality Balance in Monopoly, Hugh Sibly

2007-10 Rationing Recreational Access to Wilderness and Other Natural Areas, Hugh Sibly

2006-01 Estimates of Technology and Convergence: Simulation Results, Graeme Wells and Thanasis Stengos

2006-02 Dietary Pattern, Calorie Intake and Undernourishment: The Vietnamese Experience, Vinod Mishra and Ranjan Ray

2006-03 Early Retirement in the Funding of Australian Retirement, Bruce Felmingham, Yong Hong Yan, Natalie Jackson and Maggie Walter

2006-04 The Cyclical and Trend Behaviour of Australian Investment and Savings, Bruce Felmingham and Arusha Cooray

2006-05 Education and Child Labour: A Global Perspective, Ranjan Ray

2006-06 A Regular Demand System with Commodity-Specific Demographic Effects, Paul Blacklow, Russell Cooper, Roger Ham and Keith McLaren

2006-07 Fertility Choices of Australian Couples, Paul Blacklow

2006-08 Is there Gender Bias in the Household's time Allocation in a Developing Country? The Indian Experience, Pushkar Maitra and Ranjan Ray

2006-09 Examining Quality Distortion, Hugh Sibly

2006-10 The Day-of-the-Week (DoW) Efficiency of the S\&P/ASX20 Index and it's Component Stocks Nagaratnam Jeyasreedharan

2006-11 Convergence to the Law of One Price: Evidence From Cross-Listed Chinese Stocks, Yong Hong Yan, Graeme Wells and Bruce Felmingham

2005-01 Investment and Savings Cycles and Tests for Capital Market Integration, Arusha Cooray and Bruce Felmingham

2005-02 The Efficiency of Emerging Stock Markets: Empirical Evidence from the South Asian Region, Arusha Cooray and Guneratne Wickremasinghe

2005-03 Error-Correction Relationships Between High, Low and Consensus Prices, Nagaratnam Jeyasreedharan

2005-04 Tests for RIP Among the G7 When Structural Breaks are Accommodated, Bruce Felmingham and Arusha Cooray

2005-05 Alternative Approaches to Measuring Temporal Changes in Poverty with Application to India, Dipankor Coondoo, Amita Majumder, Geoffrey Lancaster and Ranjan Ray

2005-06 Intertemporal Household Demographic Models for Cross Sectional Data, Paul Blacklow

2005-07 Some Recent Evidences about the Global Integration of Chinese Share Markets, Yong Hong Yan and Bruce Felmingham

2005-08 Managerial Objectives and Use Limits on Resource-Based Recreations, Hugh Sibly

2005-09 The Feldstein-Horioka Model Re-Visted for African Countries, Arusha Cooray and Dipendra Sinha

2005-10 Analysis of Changes in Food Consumption and their Implications for Food Security and Undernourishment: The Indian Experience in the 1900s, Ranjan Ray

2005-11 An Extended Feldstein-Horioka Test for the Degree of Capital Mobility, Alexis Wadsley, Bruce Felmingham and Arusha Cooray

2005-12 Extreme-Valued Distributional Relationships in Asset Prices, Nagaratnam Jeyasreedharan

Copies of the above mentioned papers and a list of previous years' papers are available on request from the Discussion Paper Coordinator, School of Economics and Finance, University of Tasmania, Private Bag 85, Hobart, Tasmania 7001, Australia. Alternatively they can be downloaded from our home site at http://www.utas.edu.au/ecofin 